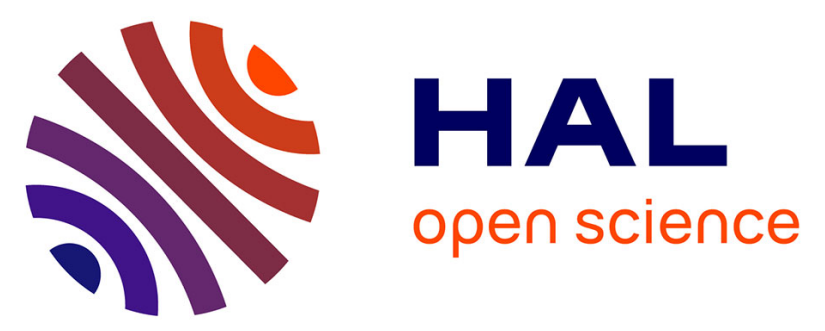

\title{
Effective prophylaxis of thromboembolic complications with low molecular weight heparin in relapsed multiple myeloma patients treated with lenalidomide and dexamethasone
}

Ulrike Klein, Florentina Kosely, Jens Hillengass, Michael Hundemer, Stefan Schmitt, Kai Neben, Thomas Moehler, Ute Hegenbart, Anthony D. Ho, Hartmut Goldschmidt

\section{- To cite this version:}

Ulrike Klein, Florentina Kosely, Jens Hillengass, Michael Hundemer, Stefan Schmitt, et al.. Effective prophylaxis of thromboembolic complications with low molecular weight heparin in relapsed multiple myeloma patients treated with lenalidomide and dexamethasone. Annals of Hematology, 2008, 88 (1), pp.67-71. 10.1007/s00277-008-0561-1 . hal-00477963

\section{HAL Id: hal-00477963 https://hal.science/hal-00477963}

Submitted on 30 Apr 2010

HAL is a multi-disciplinary open access archive for the deposit and dissemination of scientific research documents, whether they are published or not. The documents may come from teaching and research institutions in France or abroad, or from public or private research centers.
L'archive ouverte pluridisciplinaire HAL, est destinée au dépôt et à la diffusion de documents scientifiques de niveau recherche, publiés ou non, émanant des établissements d'enseignement et de recherche français ou étrangers, des laboratoires publics ou privés. 


\title{
Effective prophylaxis of thromboembolic complications with low molecular weight heparin in relapsed multiple myeloma patients treated with lenalidomide and dexamethasone
}

\author{
Ulrike Klein • Florentina Kosely • Jens Hillengaß • \\ Michael Hundemer • Stefan Schmitt • Kai Neben • \\ Thomas Moehler • Ute Hegenbart • Anthony D. Ho • \\ Hartmut Goldschmidt
}

Received: 14 April 2008 / Accepted: 9 July 2008 / Published online: 31 July 2008

(C) Springer-Verlag 2008

\begin{abstract}
The immunomodulatory drugs thalidomide and lenalidomide have enhanced activity in patients with multiple myeloma (MM). Their efficacy is increased with the addition of dexamethasone, but significant rates of venous thromboembolism (VTE) are a severe side effect. Based on this evidence, it is recommended that VTE prophylaxis be prescribed in these patients. However, the optimal prophylaxis remains controversial. We analyzed 45 patients with relapsed MM who were treated with lenalidomide and dexamethasone at our center. The 45 patients received a total number of 192 cycles, respectively a median of three cycles; the median dosage of dexamethasone was $240 \mathrm{mg}$ per cycle. All patients received prophylactic anticoagulation with low molecular weight heparin (LMWH). Moreover, $86.6 \%$ of patients had at least one additional VTE risk factor beside the myeloma-related risk. One out of 45 patients developed a deep vein thrombosis and pulmonary embolism. None of the other 44 patients had clinical signs of thrombosis or embolism and none of all patients experienced complications or side effects due to anticoagulation. Our results indicate that prophylactic anticoagulation with LMWH is safe and
\end{abstract}

U. Klein $(\bowtie) \cdot$ F. Kosely $\cdot$ J. Hillengaß $\cdot$ M. Hundemer $\cdot$

S. Schmitt · K. Neben · T. Moehler · U. Hegenbart • A. D. Ho •

H. Goldschmidt

Department of Internal Medicine V, University of Heidelberg,

INF 410,

69120 Heidelberg, Germany

e-mail: Ulrike.Klein2@med.uni-heidelberg.de

H. Goldschmidt

National Center for Tumor Diseases Heidelberg,

INF 350,

69120 Heidelberg, Germany effective. Therefore, we propose LMWH should be used in patients being treated with lenalidomide and dexamethasone at least for the first 3 months of treatment until randomized trials have proven the equality of other pharmacological prophylaxis.

Keywords IMiDs $\cdot$ Lenalidomide $\cdot$ Low molecular weight heparin · Multiple myeloma $\cdot$ Prophylaxis · Thrombosis

\section{Introduction}

Venous thromboembolism (VTE) is well known to be a common complication in cancer patients and represents a significant cause of morbidity and mortality [1]. Large studies of patients with hematological malignancies have demonstrated the increased risk of VTE in this population [2]. Of these patients, multiple myeloma (MM) patients have the highest risk of thromboembolic complications [3]. The general incidence of VTE in newly diagnosed MM patients is higher than in relapsed/refractory patients $[4,5]$. The risk of developing a VTE is highest during induction therapy while patients still have a high tumor burden $[6,7]$. Beside the myeloma-related risk factors in itself, the appearance of various other individual risk factors like age, obesity, central venous catheters, previous history of VTE, diabetes, chronic renal insufficiency, heart disease, and the kind of anti-myeloma treatment are known.

Thalidomide and lenalidomide have shown significant activity in the treatment of MM $[5,8]$. Nevertheless, the associated side effect of VTE is a severe complication in the treatment with these immunomodulatory drugs. Published data for lenalidomide/dexamethasone demonstrate high rates of VTE [9]. The risk significantly increases in 
analogy to the experience with thalidomide in case of combination with chemotherapy or erythropoietin [10]. In two recently published phase III studies of lenalidomide/ dexamethasone combination therapy with no recommended anticoagulation, VTE occurred more often in the lenalidomide group compared to the placebo group with $14.7 \%$ vs. $3.4 \%$ (MM-009) and $11.4 \%$ vs. $4.6 \%$ (MM-010) [8, 11]. A randomized double-blind, placebo-controlled trial for previous untreated $\mathrm{MM}$ patients compared dexamethasone in combination with lenalidomide vs. high dose dexamethasone alone. A high initial rate of VTE was seen in newly diagnosed myeloma patients treated with lenalidomide/ dexamethasone, therefore acetysalicyl acid (ASA) $325 \mathrm{mg}$ was mandated. Of 198 patients, 25 patients developed a VTE (12.6\%) during initial therapy with lenalidomide/ dexamethasone or after crossover while seven patients (3.5\%) had VTE in the high dose dexamethasone arm [12].

Analyzing published data for newly diagnosed patients, the risk is lower at the time of relapse with up to $15 \%$ than in newly diagnosed patients with a rate of more than $20 \%$ $[13,14]$. Nevertheless, the rate of $10-15 \%$ VTE complications is significantly high in relapsed MM patients. Reducing the incidence of VTE is critical to patient survival, as approximately one fourth of pulmonary embolism (PE) cases present as sudden death [15].

The heterogeneity of published data does not allow a particular recommendation for VTE prophylaxis for patients receiving an immunomodulatory-based therapy. The optimal pharmacological VTE prophylaxis for patients treated with a combination regime with dexamethasone or chemotherapy and immunomodulatory drugs remains controversial. Recently presented preliminary data of a randomized phase III study of enoxaparin vs. aspirin vs. low-fixed dose of warfarin in newly diagnosed MM patients treated with thalidomide-based regimes revealed that ASA patients had a higher frequency of VTE than LMWH patients, but differences did not reach statistical significance [16]. For patients with VTE risk factors, ASA may not be an adequate prophylaxis as a retrospective analysis of the MD Anderson Cancer Centre has recently shown [17].

Currently, a recommendation according to a risk assessment model based on various risk factors is discussed [18]. Especially in relapsed/refractory patients, limited data are available on the efficacy of thromboprophylaxis. We therefore performed a single center analysis regarding the use of LMWH for prevention of VTE in relapsed/refractory patients treated with lenalidomide/dexamethasone therapy.

\section{Patients and methods}

From July 2005 to January 2008, 45 patients with relapsed MM were treated with lenalidomide/dexamethasone in our department. The median age was 62 years (range 29-78 years), $21 / 45$ patients $(46.7 \%)$ were $\geq 65$ years. Twentyeight patients were male and 17 patients were female. The patients were intensively pre-treated with a median of four previous treatment regimens (range 1-11). Thirty-seven patients $(82.2 \%)$ underwent at least one autologous transplantation. Twenty-six patients $(57.8 \%)$ had a thalidomidebased therapy before initiating lenalidomide medication; 29 patients $(64.4 \%)$ were pre-treated with bortezomib. The median time from first diagnosis to lenalidomide/ dexamethasone therapy was 69 months (range 14-155 months). Twelve patients $(26.7 \%)$ had a previous medical history of VTE; nine patients $(20 \%)$ had a port catheter system during treatment with lenalidomide/dexamethasone. The distribution of other VTE risk factors like obesity, diabetes, renal insufficiency, and cardiac disease is scheduled in Table 1.

Treatment was administered with $25 \mathrm{mg}$ lenalidomide days $1-21$ and initially with $40 \mathrm{mg}$ oral dexamethasone days $1-4,9-12$, and $17-20$. After treatment of ten patients, the dosage of dexamethasone was regularly reduced to 20 mg days $1-4,9-12$, and 17-20 because of severe infectious complications in the preceding patients. The 45 patients received a total number of 192 cycles, respectively a median of three cycles per patient (range 1-17 cycles). The median dosage of dexamethasone was $240 \mathrm{mg}$ per cycle. All of the 45 patients received prophylactic anticoagulation from the start of therapy with LMWH at least for the first three cycles. Also, 167 cycles $(86.9 \%)$ were given with LMWH in which 152 cycles $(79.2 \%)$ were administered with enoxaparin: 147 cycles with enoxaparin $0.4 \mathrm{ml}$ daily subcutaneously, two cycles with enoxaparin $0.3 \mathrm{ml}$ due to renal insufficiency, and three cycles with enoxaparin $1.0 \mathrm{ml}$ because of previous severe and recurrent thrombosis of the vena cava superior. Ten cycles $(5.2 \%)$ were administered with dalteparin. Of these ten cycles, nine

Table 1 Patient characteristics

Risk factor Number $(\%)$

Previous VTE, port catheter system, age

$\geq 65$ years, obesity $(\mathrm{BMI} \geq 30$ ), high dose

dex $480 \mathrm{mg} / \mathrm{month}$, diabetes, cardiac disease, renal insufficiency Crea.-Cl. $\leq 40 \mathrm{ml} / \mathrm{min}$

\begin{tabular}{lc}
\hline Previous VTE & $12(26.7)$ \\
Port catheter system & $9(20)$ \\
Age $\geq 65$ years & $21(46.7)$ \\
obesity (BMI $\geq 30$ ) & $5(11.1)$ \\
High dose dexamethasone $480 \mathrm{mg} /$ month & $10(22.2)$ \\
Diabetes mellitus & $2(4.4)$ \\
Cardiac disease & $5(11.1)$ \\
Renal insufficiency with Crea.-Cl. $\leq 40 \mathrm{ml} / \mathrm{min}$ & $7(15.6)$ \\
No risk factor & $6(13.3)$ \\
1 risk factor & $19(42.2)$ \\
$\geq 2$ risk factors & $20(44.4)$ \\
\hline
\end{tabular}


were administered with a dosage of dalteparin 2,500 IE once daily and one cycle was given to a patient with the dosage of 5,000 IE once daily; three $(1.6 \%)$ cycles were performed with nadoparin 7,600 IE once daily. Two cycles $(1.0 \%)$ were given to one patient with a combination of ASA $100 \mathrm{mg}$ and enoxaparin $0.2 \mathrm{ml}$. ASA had already been continuously administered due to coronary heart disease before initiating medication with lenalidomide. Twenty-five cycles (13.0\%) were administered during medication with ASA $100 \mathrm{mg}$. All of these patients started with LMWH prophylaxis for at least the first three cycles but due to adverse reaction in one case and easier management of care in two other cases, prophylaxis was switched to ASA after four and five cycles, respectively. All patients were seen at least once every 2 weeks in our department and examined for clinical signs of thrombosis. At the time of analysis, 37 patients $(82.2 \%)$ were alive, 24 patients $(53.3 \%)$ were still on therapy with lenalidomide/dexamethasone while 21 patients $(46.6 \%)$ had stopped due to progressive disease or severe side effects.

\section{Results}

One of 45 patients developed a VTE (2.2\%). The 74-year-old Caucasian male had a previously diagnosed thrombosis. It had developed several years before starting the treatment with lenalidomide/dexamethasone. After the first cycle of lenalidomide/dexamethasone, he underwent surgery for a double-sided inguinal hernia. The patient was taking $100 \mathrm{mg}$ ASA regularly because of coronary heart disease. Therewith beside the myeloma-related risk, he had four additional VTE risk factors: age $\geq 65$ years, previous history of VTE, surgery, and a chronic heart disease. He was intensively pre-treated with six prior treatment regimens including autologous transplantation but no previous therapy with thalidomide had been performed. Before starting anti-myeloma treatment with lenalidomide/dexamethasone, prophylaxis was extended with additional continuous enoxaparin $20 \mathrm{mg}$ subcutaneously. Anti-myeloma treatment was administered as previously mentioned. The dosage of dexamethasone was reduced in the second cycle to $20 \mathrm{mg}$ days $1-4$. At day 20 of the second cycle, the patient developed deep vein thrombosis and pulmonary embolism (PE). Treatment with lenalidomide was stopped and changed to bendamustine. In January 2008, the patient was still alive. None of the other 44 patients had clinical signs of thrombosis or embolism and none of the patients experienced bleeding complications.

\section{Discussion}

Multiple myeloma remains incurable with conventional treatment but the development of new agents like bortezomib, thalidomide, and lenalidomide have changed the management of the disease essentially. All of these drugs have shown significant activity in the treatment of MM [8, 19]. Nevertheless, they have side effects that partly entail the end of the therapy. Venous thromboembolism is such a severe complication in the treatment with the immunomodulatory drugs thalidomide or lenalidomide (see Table 2).

With the frequent use of these drugs, VTE have attained a new clinical dimension, but the optimal pharmacological prophylaxis remains controversial [20]. For the prophylaxis of VTE in cancer patients in general, LMWH is recommended as standard of care [21]. In the absence of randomized data, ASA became a candidate for VTE prophylaxis for patients receiving lenalidomide/dexamethasone. Earlier published data may suggest that ASA is a potential drug for prevention of VTE with many advantages compared to LMWH such as oral administration, low cost, and high availability [22].

In a retrospective analysis of different trials of newly diagnosed patients, Palumbo et al. showed a rate of VTE of $2.1 \%$ for patients who were treated with melphalan/ lenalidomide/prednisone and who received a thromboprophylaxis with ASA. But it needs to be considered that dexamethasone has a much higher potency to provoke VTE than prednisone. Beside that, the dosage of dexamethasone in itself is much higher with 240 to $480 \mathrm{mg} / \mathrm{cycle}$ compared

Table 2 VTE rates in patients with multiple myeloma treated with thalidomide or lenalidomide and dexamethasone

\begin{tabular}{|c|c|c|c|c|}
\hline Study & $N$ & Therapy & Prophylaxis & VTE rate $(\%)$ \\
\hline Dimopoulos et al. [11] & 351 & Len/high dose Dex vs. Placebo/Dex & None & 11.4 vs. 4.6 \\
\hline Weber et. al $[8]$ & 353 & Len/high dose Dex vs. Placebo/Dex & None & 14.7 vs. 3.4 \\
\hline Zonder et al. [12] & 198 & Len/high dose Dex vs. high dose Dex & ASA (not initially) & 12.6 vs. 3.5 \\
\hline Rajkumar et al. [14] & 445 & Len/high dose Dex vs. Len/Dex low dose & ASA & 25 vs. 9 \\
\hline Palumbo et al. [16] & 200 (interim analysis) & Thal-based therapy & $\begin{array}{l}\text { ASA vs. LMWH vs. } \\
\text { low-fixed dose warfarin }\end{array}$ & $\begin{array}{l}9 \\
3 \\
3\end{array}$ \\
\hline Minnema et al. [24] & 211 & Thal/Adriamycin/Dex high dose (TAD) & LMWH & 8 \\
\hline Klein et al. (this study) & 45 & Len/intermediate Dex & LMWH & 2.2 \\
\hline
\end{tabular}


to $100 \mathrm{mg}$ prednisone [13]. For newly diagnosed patients who receive a dexamethasone-containing regime, ASA may not be an adequate prophylaxis as recently published data have shown [12].

The American Society of Clinical Oncology determined that a routine prophylaxis for ambulatory patients with anticoagulation is not recommended, with the exception of patients receiving thalidomide or lenalidomide. Until data of randomized studies are available, LMWH or low dose warfarin is recommended in myeloma patients who are receiving anti-angiogenic therapy in combination with chemotherapy or dexamethasone [23].

Likewise, for patients with additional risk factors beside the myeloma-related risk in itself, ASA seems to be insufficient. Taking this into account, a strategy according a risk assessment model was initiated. The panel recommends aspirin for patients with $\leq 1$ risk factor for VTE and LMWH for those with $\geq 2$ individual/myeloma-related risk factors [18]. Nevertheless, data of larger-sized trials are lacking.

We retrospectively analyzed refractory/relapsed $\mathrm{MM}$ patients who were treated in our center with lenalidomide/ dexamethasone. With a median of $240 \mathrm{mg} /$ cycle, we administered an intermediate dosage of dexamethasone. All patients received prophylactic anticoagulation with LMWH from the start of treatment. Only one case of DVT and PE occurred. The 74-year-old male received aspirin before starting the treatment with lenalidomide/ dexamethasone because of coronary heart disease. Therefore, the dosage of enoxaparin was reduced from the common dosage of 0.4 to $0.2 \mathrm{ml}$. In consideration of the experience with no observed bleeding complication, we currently determine an additional prophylaxis with enoxaparin $0.4 \mathrm{ml}$ in such patients.

Being aware of the small number of patients and a refractory/relapsed setting, the rate of 2.2\% VTE remains lower than the incidence of VTE in the dexamethasone control arms of the two randomized phase III trials with $4.6 \%$ and $3.4 \%$, respectively. Taking into account that $42.2 \%$ of patients had beside the myeloma-related risk, one more VTE-specific risk factor and an additional proportion of $44.4 \%$ even $\geq 2$ risk factors LMWH prophylaxis seems to be very effective even in patients of higher risk. Patients with no additional risk factors may be protected adequate with the administration of aspirin. Regarding no complications or severe side effects caused by the use of LMWH, we propose prophylaxis with LMWH in patients being treated with lenalidomide/dexamethasone at least during the first 3 months of therapy until randomized trials have proven the equality of other pharmacological prophylaxis. In the future, analysis of randomized trials may sustain the model for the individualized probability of VTE risk [18].
Acknowledgement We thank Frank Müller for carefully collecting data.

Conflict of Interest Disclosure The authors declare no competing financial interests.

\section{References}

1. Kakkar AK, Levine M, Pinedo HM, Wolff R, Wong J (2003) Venous thrombosis in cancer patients: insights from the FRONTLINE survey. Oncologist 8(4):381-388 doi:10.1634/theoncologist. 8-4-381

2. Baron JA, Gridley G, Weiderpass E, Nyren O, Linet M (1998) Venous thromboembolism and cancer. Lancet 351(9109):10771080 doi:10.1016/S0140-6736(97)10018-6

3. Blom JW, Doggen CJ, Osanto S, Rosendaal FR (2005) Malignancies, prothrombotic mutations, and the risk of venous thrombosis. JAMA 293(6):715-722 doi:10.1001/jama.293.6.715

4. Weber D, Rankin K, Gavino M, Delasalle K, Alexanian R (2003) Thalidomide alone or with dexamethasone for previously untreated multiple myeloma. J Clin Oncol 21(1):16-19 doi:10.1200/ JCO.2003.03.139

5. Neben K, Moehler T, Benner A, Kraemer A, Egerer G, Ho AD et al (2002) Dose-dependent effect of thalidomide on overall survival in relapsed multiple myeloma. Clin Cancer Res 8 (11):3377-3382

6. Heit JA, Silverstein MD, Mohr DN, Petterson TM, O'Fallon WM, Melton LJ III (2000) Risk factors for deep vein thrombosis and pulmonary embolism: a population-based case-control study. Arch Intern Med 160(6):809-815 doi:10.1001/archinte.160.6.809

7. Zangari M, Anaissie E, Barlogie B, Badros A, Desikan R, Gopal $\mathrm{AV}$ et al (2001) Increased risk of deep-vein thrombosis in patients with multiple myeloma receiving thalidomide and chemotherapy. Blood 98(5):1614-1615 doi:10.1182/blood.V98.5.1614

8. Weber DM, Chen C, Niesvizky R, Wang M, Belch A, Stadtmauer EA et al (2007) Lenalidomide plus dexamethasone for relapsed multiple myeloma in North America. N Engl J Med 357 (21):2133-2142 doi:10.1056/NEJMoa070596

9. Knight R, DeLap RJ, Zeldis JB (2006) Lenalidomide and venous thrombosis in multiple myeloma. N Engl J Med 354(19):20792080 doi:10.1056/NEJMc053530

10. Rajkumar SV, Blood E (2006) Lenalidomide and venous thrombosis in multiple myeloma. N Engl J Med 354(19):20792080 doi:10.1056/NEJMc053530

11. Dimopoulos M, Spencer A, Attal M, Prince HM, Harousseau JL, Dmoszynska A et al (2007) Lenalidomide plus dexamethasone for relapsed or refractory multiple myeloma. N Engl J Med 357 (21):2123-2132 doi:10.1056/NEJMoa070594

12. Zonder JA, Crowley J, Hussein MA, Bolejack V, Moore DF, Whittenberger BF et al Superiority of lenalidomide (Len) plus high-dose dexamethasone (HD) compared to HD alone as treatment of newly-diagnosed multiple myeloma (NDMM): results of the randomized, double-blinded, placebo-controlled SWOG Trial S0232. ASH Annual Meeting Abstracts 2007 November 16;110(11):77

13. Palumbo A, Rus C, Zeldis JB, Rodeghiero F, Boccadoro M (2006) Enoxaparin or aspirin for the prevention of recurrent thromboembolism in newly diagnosed myeloma patients treated with melphalan and prednisone plus thalidomide or lenalidomide. J Thromb Haemost 4(8):1842-1845 doi:10.1111/j.1538-7836. 2006.02059.x 
14. Rajkumar SV, Jacobus S, Callander N, Fonseca R, Vesole D, Williams $\mathrm{M}$, et al A randomized trial of lenalidomide plus high-dose dexamethasone (RD) versus lenalidomide plus low-dose dexamethasone (Rd) in newly diagnosed multiple myeloma (E4A03): a trial coordinated by the Eastern Cooperative Oncology Group. ASH Annual Meeting Abstracts 2007 November 16;110(11):74

15. Heit JA, Silverstein MD, Mohr DN, Petterson TM, O'Fallon WM, Melton LJ III (1999) Predictors of survival after deep vein thrombosis and pulmonary embolism: a population-based, cohort study. Arch Intern Med 159(5):445-453 doi:10.1001/archinte.159.5.445

16. Palumbo A, Cavo M, Bringhen S, Perrone G, Magarotto V, Patriarca F, et al Prospective, randomized, phase III study of enoxaparin versus aspirin versus low-fixed-dose of warfarin in newly diagnosed myeloma patients treated with thalidomidecontaining regimens. ASH Annual Meeting Abstracts 2007 November 16;110(11):310.

17. Wright JA, Weber D, Thomas SK, Wang M, Alexanian R, Hawkins VE, et al Characteristics of patients experiencing thromboembolic events during treatment for multiple myeloma: aspirin may not be adequate thromboprophylaxis in patients with multiple risk factors. ASH Annual Meeting Abstracts 2007 November 16;110(11):1882

18. Palumbo A, Rajkumar SV, Dimopoulos MA, Richardson PG, San MJ, Barlogie B et al (2008) Prevention of thalidomide- and lenalidomide-associated thrombosis in myeloma. Leukemia 22 (2):414-423 doi:10.1038/sj.leu.2405062

19. Richardson PG, Sonneveld P, Schuster M, Irwin D, Stadtmauer E, Facon $T$ et al (2007) Extended follow-up of a phase 3 trial in relapsed multiple myeloma: final time-to-event results of the
APEX trial. Blood 110(10):3557-3560 doi:10.1182/blood-200608-036947

20. Durie BGM, Richardson P, Palumbo A, Dimopoulos MA, Cavo M, Hajek R et al (2006) Deep vein thrombosis in myeloma: estimate of prevalence and recommendations for therapy based upon a survey of members of the International Myeloma Working Group (IMWG). Blood 108(11):3571 ASH Annual Meeting Abstracts

21. Geerts WH, Pineo GF, Heit JA, Bergqvist D, Lassen MR, Colwell $\mathrm{CW}$ et al (2004) Prevention of venous thromboembolism: the Seventh ACCP Conference on Antithrombotic and Thrombolytic Therapy. Chest 126(Suppl 3):338S-400S doi:10.1378/chest. 126.3_suppl.338S

22. Baz R, Li L, Kottke-Marchant K, Srkalovic G, McGowan B, Yiannaki E et al (2005) The role of aspirin in the prevention of thrombotic complications of thalidomide and anthracycline-based chemotherapy for multiple myeloma. Mayo Clin Proc 80 (12):1568-1574

23. Lyman GH, Khorana AA, Falanga A, Clarke-Pearson D, Flowers C, Jahanzeb M et al (2007) American Society of Clinical Oncology guideline: recommendations for venous thromboembolism prophylaxis and treatment in patients with cancer. J Clin Oncol 25(34):5490-5505 doi:10.1200/JCO.2007.14.1283

24. Minnema MC, Breitkreutz I, Auwerda JJ, van der Holt B, Cremer FW, van Marion AMW, Westveer PHM, Sonneveld P, Goldschmidt H, Lokhorst HM (2004) Prevention of venous thromboembolism with low molecular-weight heparin in patients with multiple myeloma treated with thalidomide and chemotherapy. Leukemia 18 (12):2044-2046 doi:10.1038/sj.leu.2403533 